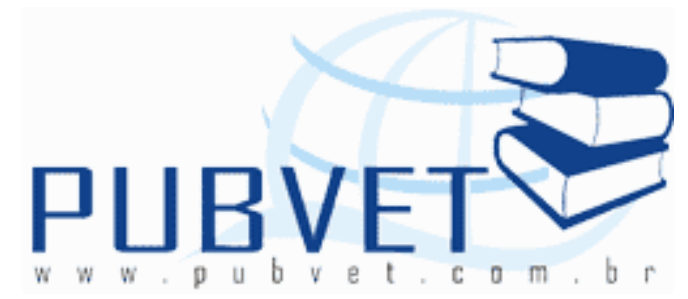

PUBVET, Publicações em Medicina Veterinária e Zootecnia.

\title{
Gastroenterite eosinofílica canina - revisão de literatura
}

\section{Priscila Aquino Brisolla de Barros ${ }^{1}$, Bruno Roque Lima ${ }^{2}$, Adriana Ventura ${ }^{3}$,} Cezar Augusto Infante ${ }^{4}$

${ }^{1}$ Medica Veterinária - Residente no Centro de Referência em Veterinária, São Vicente - SP, Brasil

${ }^{2}$ Mestrado em Cirurgia UNESP, Jaboticabal - SP, Brasil

${ }^{3}$ Medica Veterinária

${ }^{4}$ Pós-graduação em Cirurgia Metodista, São Paulo - SP, Brasil

\section{Resumo}

A gastroenterite eosinofílica (GEE) é uma doença de caráter inflamatório que pode ocorrer em qualquer parte do trato gastrointestinal, caracterizado por um infiltrado de células eosinofílicas, onde a sintomatologia varia de vômitos intermitentes à diarreia, perda de peso, anorexia e prostração. Tem etiologia desconhecida, mas suspeita-se de uma reação de hipersensibilidade do tipo I (imediata) contra algum antígeno presente no lúmen intestinal. O diagnóstico é feito através do exame físico e exames laboratoriais, mas a laparotomia é necessária para biópsia, na qual permite o diagnóstico definitivo. O tratamento consiste na combinação no uso de corticoides, dieta e antibióticos. Esta revisão visa trazer informações com o objetivo de identificar os sintomas e opções de 
BARROS, P.A.B. et al. Gastroenterite eosinofílica canina: revisão de literatura. PUBVET, Londrina, V. 7, N. 16, Ed. 239, Art. 1575, Agosto, 2013.

tratamento para a gastroenterite eosinofilica, a qual é uma doença rara com poucos estudos relatados.

Palavras-chave: Gastroenterite eosinofílica, caninos, infiltrado eosinofílico, diarreia crônica e vômitos intermitentes.

\section{Eosinophilic gastroenteritis canine - literature review}

\section{Abstract}

The eosinophilic gastroenteritis (AGE) is a inflammatory disease which can occur anywhere in the gastrointestinal tract, characterized by an infiltration of eosinophilic cells, where the symptoms varies from intermittent vomiting to diarrhea, weight loss, anorexia and prostration. Has unknown etiology, but it is suspects of a type 1 hypersensitivity reaction (immediate) against any antigen present in the intestinal lumen. The diagnosis is made through physical examination and laboratorial tests, but the laparotomy is required for biopsy which allows the definitive diagnosis. The treatment consist in combining the use of corticoids, diets and antibiotics. This review aims to bring information in order to identify its symptoms and treatment options, of eosinophilic gastroenteritis, which is a rare disease, with few studies reported.

Keywords: Eosinophilic Gastroenteritis, canines, eosinophilic infiltrate, chronic diarrhea, intermittent vomiting.

\section{INTRODUÇÃO}

Enterite consiste na inflamação no intestino por diferentes causas, podendo atingir toda a parte do trato intestinal ou somente atingir o intestino delgado. Quando acomete todo o trato digestivo inferior é denominada de gastroenterite, e como consequência, o primeiro sinal da enterite é o surgimento de diarreia, e esta na sua maioria sanguinolenta ${ }^{1,2}$.

Doenças gastroentéricas compõem grande parte da casuística da clínica médica de pequenos animais, e esse quadro possui, entre outras, várias 
BARROS, P.A.B. et al. Gastroenterite eosinofílica canina: revisão de literatura. PUBVET, Londrina, V. 7, N. 16, Ed. 239, Art. 1575, Agosto, 2013.

etiologias: virais, parasitárias, bacterianas, intoxicações em geral e alimentares, entre as quais as enterites virais ocupam um papel importante desde 1970, representando mais de $80 \%$ dos casos de gastroenterite canina e é considerada uma das causas mais comuns de diarreia infecciosa em cães com menos de seis meses de idade, e responsáveis por índices consideráveis de morbidade e de mortalidade em cães de todo o mundo ${ }^{2,3}$.

A mais comum é a infecção pelo Parvovírus Canino, possuindo um grau de severidade maior e acometendo $50 \%$ dos animais com essa manifestação clínica ${ }^{3}$.

Os cães são frequentemente infectados por parasitas gastrointestinais que podem infectar o homem. Por exemplo, o ascarídeo Toxocara canis e o ancilostomídeo Ancylostoma caninum, são os principais agentes etiológicos da Larva Migrans Visceral (LMV) e Larva Migrans Cutânea (LMC), respectivamente ${ }^{4}$.

O presente trabalho foi realizado com o objetivo de revisar aspectos importantes da gastroenterite eosinofílica, e apresentar formas de diagnóstico e tratamento dessa afecção.

\section{ETIOPATOGENIA}

A etiologia da GEE é desconhecida, mas suspeita-se de uma reação de hipersensibilidade do tipo I (imediata) contra algum antígeno presente no lúmen intestinal; essa hipersensibilidade induz a degranulação de mastócitos, havendo a liberação de mediadores da inflamação e, consequentemente, atração de eosinófilos, sendo que suspeita-se que alguns alergenos presentes na dieta têm sido implicados, por exemplo, carne bovina e leite ${ }^{5,6,7}$.

O aumento de células IgE positivas em cães doentes comparados a cães saudáveis é um outro aspecto que também sugere o envolvimento de reações de hipersensibilidade na patogênese da GE, assim como o aumento da concentração de eosinófilos e mastócitos nestes cães ${ }^{8}$. 
BARROS, P.A.B. et al. Gastroenterite eosinofílica canina: revisão de literatura. PUBVET, Londrina, V. 7, N. 16, Ed. 239, Art. 1575, Agosto, 2013.

Migração de parasitas podem também induzir a doença, sendo que larvas de ascarídeos em um hospedeiro imune pode ser a causadora em alguns casos de enterite eosinofílica em cães ${ }^{5,6}$.

Em animais os sinais clínicos são semelhantes aos de outras gastroenterites crônicas e podem incluir vômitos intermitentes, apresentando envolvimento gástrico ou duodenal, intestino delgado e/ou intestino grosso, inapetência, perda de peso e anorexia. Hematêmese, hematoquezia ou melena podem estar presentes como resultado da ulceração gastrintestinal, e alguns cães apresentam concomitante doença do trato respiratório eosinofílica, podendo também ser vistas alergias cutâneas de origem alimentar ${ }^{9,6,7}$.

\section{DIAGNÓSTICO}

A avaliação laboratorial traz como principal achado a eosinofilia, um achado inconsistente em cães pelo fato de ser comum em animais com doença gastrointestinal de todos os tipos.O diagnostico por imagem (radiografia e ultra-sonografia) auxilia na deteç̧ão de possíveis alterações abdominais e torácicas ${ }^{10,6}$.

A biópsia intestinal é necessária para um diagnóstico definitivo, embora os sinais clínicos e o exame físico sejam sugestivos. As lesões microscópicas na mucosa intestinal consistem em infiltrados celulares inflamatórios difusos em que o eosinófilo é o tipo celular predominante sendo que ocorrem difusamente na lâmina própria, abaixo do epitélio, ao redor dos vasos linfáticos das vilosidades. O envolvimento da submucosa pode ser mínimo, mas em alguns casos, os eosinófilos se estendem não só até a submucosa, mas também até as camadas musculares, e geralmente não são observadas vilosidades rombas ou atrofiadas ${ }^{10,5}$.

O diagnóstico diferencial da gastroenterite eosinofílica deve incluir outras doenças sistêmicas com envolvimento intestinal como intussuscepção, tumor, pancreatite, infestações por giárdia e nematódeos ${ }^{6}$. 
BARROS, P.A.B. et al. Gastroenterite eosinofílica canina: revisão de literatura. PUBVET, Londrina, V. 7, N. 16, Ed. 239, Art. 1575, Agosto, 2013.

\section{TRATAMENTO}

O tratamento para a enterite eosinofílica canina é amplamente empírico devido à má compreensão da etiopatogenia e falta de ensaios terapêuticos. A administração de corticosteróides, azatioprima, antibióticos e dietas específicas, isoladamente ou em combinação, são atualmente, os principais tratamentos para todos os tipos histológicos de enterite eosinofílica humana. A eficácia dessas abordagens não tem sido determinada na espécie canina ${ }^{6}$.

Uma variedade de dietas antialérgicas utilizando proteína de peixe, cordeiro, peru encontra-se disponíveis comercialmente. Recentemente, dietas ricas em proteínas hidrolisadas foram introduzidas com resultados promissores, ocasionando a cura clínica do paciente ${ }^{10,7}$.

A Ciprofloxacina e o metronidazol são comumente usados em humanos, contudo, na medicina veterinária, o metronidazol é utilizado isoladamente no tratamento da GEE. A eficácia do metronidazol pode não só estar relacionado com a sua atividade anti-bacteriana, mas também aos seus efeitos imunomoduladores sobre a imunidade mediada por células e em casos de colite ulcerativa ${ }^{10}$.

As drogas imunossupressoras são atualmente muito utilizadas nos casos de GEE em cães e gatos. Os glicocorticóides são usados com mais frequência, e a prednisona ou prednisolona são os medicamentos de primeira escolha, em dosagem inicial de $2,0 \mathrm{mg} / \mathrm{kg}$ a cada 12 horas por duas semanas, diminuindose a dose gradativamente usando comumente também a azatioprina, na dose de $1 \mathrm{mg} / \mathrm{kg}$, em combinação com glicocorticóides, quando sua inicial resposta é fraca, existem recidivas ou efeitos colaterais de esteróides etsao presentes. No entanto, sua atividade pode ser de aparecimento tardio (até 3 semanas) e, dada a sua ação mielossupressora, é necessário monitorização hematológica regular ${ }^{10}$.

Outras drogas imunossupressoras incluem metotrexato e ciclosporina, sendo o metotrexato eficaz no tratamento de humanos, em um relato de caso recente sugeriu eficácia em doença intestinal inflamatória canina e a 
BARROS, P.A.B. et al. Gastroenterite eosinofílica canina: revisão de literatura. PUBVET, Londrina, V. 7, N. 16, Ed. 239, Art. 1575, Agosto, 2013.

ciclosporina, recentemente, foi adaptada por muitos como um tratamento para a doença refratária tendo a confirmação de sua eficácia em tais casos, porém a principal limitação para a sua utilização é o seu custo ${ }^{10}$.

\section{CONSIDERAÇÕES FINAIS}

A gastroenterite eosinofílica é uma doença rara, que muitas vezes passa desapercebida pelos clínicos. Na suspeita desta enfermidade, o médico veterinário não deve se ater apenas ao exame clínico, mas também fazer uso de exames complementares, pois a enterite eosinofilica pode estar relacionada a doenças sistêmicas ou parasitárias. A biópsia intestinal para exame histopatológico é o único diagnóstico definitivo desta doença. Uma vez diagnosticada, o tratamento deve ser iniciado imediatamente com o uso de corticoides, preferencialmente prednisona, em doses imunossupressoras avaliando a evolução clínica do paciente ao longo do tratamento.

\section{REFERÊNCIAS BIBLIOGRÁFICAS}

01- OLIVEIRA, E. C. Achados patológicos e avaliação imunoistoquímica em cães com parvovirose canina. Dissertação (Mestrado em Ciências Veterinárias) - Universidade Federal do Rio Grande do Sul.

02- MENDES, R. S.; SOUZA, A. P.; SILVA, R. M. N.; BORGES, O. M. M.; TORRES, L. M.; DANTAS, A. J. F. P. Perfil hematológico e bioquímico de cães com gastroenterite hemorrágica por parvovírus diagnosticados pelo método de imunocromatografia. Acta Veterinaria Brasilica, v.5, n.3, p.278-283, 2011.

03- CORONA, A. L. V. ; MANHOSO, F. F. R. Utilização da Homeopatia no tratamento da gastroenterite canina. Pesquisa homeopática, v. 20, n. 1, 2002.

04- VASCONCELLOS, M. C.; BARROS, J. S. L.; OLIVEIRA, C. S. Parasitas gastrointestinais em cães institucionalizados no Rio de Janeiro, RJ. Revista Saúde Pública, v. 40, n. 2, p. 321323, 2006.

05- ÁVila, V. P. F.; ESMERAldino, A. T.; BeRNARdi, L.; FALlaVenA, L. C. B. RODRIGUES, N.C., Enterite eosinofílica canina- relato de caso. In: CONBRAVET 2008 <www.sovergs.com.br/conbravet2008/anais/cd/resumos/R0593-3.pdf. $>$ 
06- FONSECA-ALVES, C. E.; CORRÊA, A. G.; ELIAS, F. Eosinophilic gastroenteritis in basset hound dog. Open Journal of Animal Sciences, v. 2, n. 2, p. 110-112, 2012.

07- NELSON R. W.; COUTO C. G. Distúrbios do trato intestinal. In: Medicina Interna de Pequenos Animais. 3 . ed. Rio de Janeiro: Elsevier, 2006, pág. 433 - 434.

08- CASCON, C. M. Avaliação clínica, endoscópica e histopatológica de cães com doença inflamatória intestinal. Dissertação (Mestrado em Clínica e Reprodução Animal) Universidade Federal Fluminense, 2011.

09- $\quad$ MCTAVISH, S. Eosinophilic gastroenteritis in a dog. Canadian Veterinary Journal, v. 43, n. 6, p. 463-465, 2002.

10- GERMAN, A. J. Update On Inflamatory Bowel Disease. The North American Veterinary Conference- janeiro, 2005 - Small animal - gastroenterolgy. In: <http://www.ivis.org/proceedings/wsava/2006/art_lectures/GERMAN1.pdf?LA=1> . 